\title{
Cost-system functionality and the performance of the Malaysian palm oil industry
}

\begin{abstract}
Purpose: The purpose of this paper is to investigate the relationship between cost-system functionality and the performance of oil-palm enterprises in Malaysia, as well as whether manager's perceived usefulness of cost information mediates the cost-system functionalityperformance relationship.

Design/methodology/approach: A structured questionnaire is used to gather data from oilpalm enterprises located in Sarawak.

Findings: The results indicate that the cost relevance/timeliness dimension of cost-system functionality significantly enhances the performance of oil-palm enterprises. However, manager's perceived usefulness of cost information only partially mediates the cost-system functionality-non-financial performance relationship, and this is possibly due to the nature of control over the estate operations by the head office.

Research limitations/implications: Owing to the small-sample size and because the oil-palm enterprises are located only in Sarawak, the generalisability of the results may be limited. Besides, the findings are based on the estate setting whereby decisions made are relatively structured and therefore, they may not apply in less-structured decision-making settings.

Originality/value: Past findings on the causal link between cost-system functionality and performance are mixed. However, high-functional cost systems are expected to be more cost beneficial when environment is highly uncertain. The palm oil industry operates in a highly turbulent economic environment due to serious external challenges and it is expected to benefit from high-functional cost systems. Unlike previous studies based on firms from diverse industries, the operational homogeneity of the oil-palm enterprises in this paper enables the effects of cost-system functionality on performance to be examined in a more controlled setting. By analyzing the attributes of cost-system functionality into two major dimensions, this paper shows that performance could be enhanced only through provision of relevant and timely cost information.
\end{abstract}

Keyword: Cost accounting; Organizational performance; Malaysia 